Special issue of the 3rd International Conference on Computational and Experimental Science and Engineering (ICCESEN 2016)

\title{
A Review of MPPT Algorithms for Partial Shading Conditions
}

\author{
Z. ERDEM* \\ Sakarya University, Department of Electrical and Electronics Engineering, Sakarya, Turkey
}

\begin{abstract}
Maximum power point tracker in a photovoltaic system allows to maximize the energy drawn from the connected photovoltaic modules. In the partial shade conditions there can be more than one maximum point in photovoltaic output power curve. The solution for this situation is a maximum power point tracker algorithm, which finds the global maximum. In literature, there is a large number of studies on maximum power point trackers. Therefore designers are drowning in a sea of knowledge. This study eliminates similar studies and classified them into groups, and at the end of the study a comparison table is given to guide the designers in the performance information of the selected studies. This study aims to guide the designers to make a sensible selection of a maximum power point tracker algorithm for partial shade conditions.
\end{abstract}

DOI: 10.12693/APhysPolA.132.1128

PACS/topics: 87.55.kd, 02.60.Gf, 84.60.Jt

\section{Introduction}

In the last decade, the lack of new conventional energy sources, reveals the significance of the renewable sources [1]. Solar energy is one of the promising renewable types of energy, which is coming from an unlimited solar source - the Sun and can be directly converted to electrical energy by photovoltaic (PV) modules $[2,3]$. PV cells have non-linear characteristics which are affected by irradiance level, temperature, total residence etc.

Under uniform insolation there is only one maximum point in the $P-V$ curve. Maximum power point trackers (MPPT) in PV systems are responsible for detecting the maximum power point (MPP) and reaching it by the PV modules [4]. Conventional MPPT techniques track well the MPP under zero-shading conditions [5], however when partial shade condition (PSC) occurs, these methods are trapped at local maximum. During PSC two or more MPP take place in $P-V$ curves, which forces the researchers to find new techniques for MPPTs under PSC.

This study reviews the literature on MPPT methods under PSC, published in the last decade. The studies selected for revision are grouped, investigated and compared by true global MPP, speed, implementation complexity, efficiency and cost. The comparison table is given in the related section, which could assist the designers to make the right choice for their specific applications.

\section{PV module characteristics under PSC}

In a PV system, PV modules are built using series and parallel connection of the PV cells, and similarly, a PV array consists of PV modules, connected in series or

\footnotetext{
*e-mail: zekiye@sakarya.edu.tr
}

in parallel. In uniform insolation case, the total maximum output power of a PV array is equal to the sum of the maximum power values of all individual modules. Under PSC, the power of shaded modules decreases and on the output power curve of the PV array maximum power points with different maximum levels appear. In this section, in order to explain the partial shade effect, first the characteristic of the model of the PV array is given, and secondly the effect of PSC is shown using simulations.

\subsection{Model of the PV array}

An equivalent model of single-diode $\mathrm{PV}$ cell is given in Fig. 1 [6]. In the circuit $I_{\mathrm{ph}}$ is PV current source; $I_{\mathrm{D}}$ is diode current, $I_{\mathrm{SH}}$ is parallel resistance current, $R_{\mathrm{SH}}$ represents the leakage across the p-n junction, which is required to be as high as possible, $R_{\mathrm{S}}$ is the sum of resistances due to all components that come in the path of current, which is required to be as low as possible, $I_{\text {cell }}$ is output current of the $\mathrm{PV}$ cell, $V_{\text {cell }}$ is output voltage of the PV cell, $G$ is insolation level and $T$ is cell temperature.

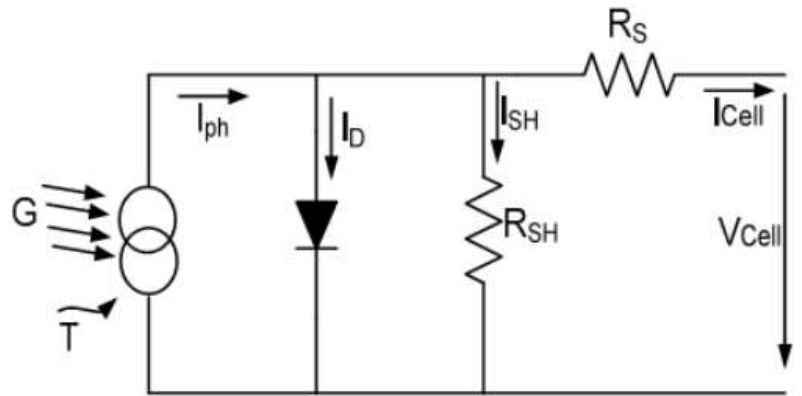

Fig. 1. Equivalent circuit of PV cell.

$$
\begin{aligned}
& I_{\text {cell }}=I_{\mathrm{ph}}-I_{0}\left[\exp \left(\frac{q V_{\text {cell }}+q R_{\mathrm{S}} I_{\text {cell }}}{N_{\mathrm{S}} k_{\mathrm{S}} T a}-1\right)\right. \\
& \left.-\frac{V_{\text {cell }}+R_{\mathrm{S}} I_{\text {cell }}}{R_{\mathrm{SH}}}\right]
\end{aligned}
$$


where $I_{0}$ is the saturation current, $a$ is the diode factor, $k_{\mathrm{S}}$ is Boltzmann's constant, $q$ is charge of an electron and $N_{\mathrm{S}}$ is number of cells in series. The output current of the $\mathrm{PV}$ module is denoted as $I_{\mathrm{pv}}$ and it depends on parallel connection of PV cells. Similarly, the output voltage of $\mathrm{PV}$ module is denoted as $V_{\mathrm{pv}}$ and it depends on serial connection of PV cells.

\subsection{PSC effect on $P V$ array}

A schematic diagram and a photograph of PV array under PSC are given in Fig. 2, where $m$ is the number of modules connected in series in each branch and $n$ is the number of parallel branches in the array. As shown in Fig. 2a, some of the modules are under different levels of shading.
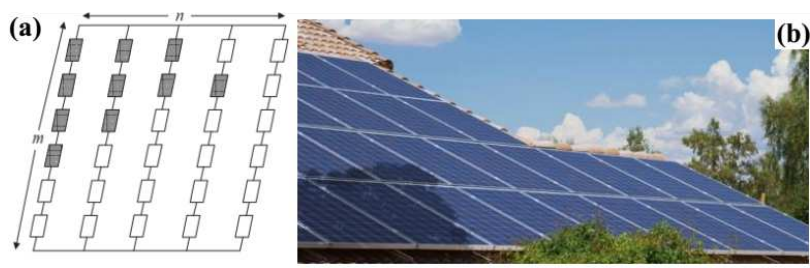

Fig. 2. (a) The schematic model of PV array under PSC and (b) real PSC in a PV array.

In this paper, the simulated PV array under PSC is arranged with four $\mathrm{PV}$ modules are follows: $P_{\max }=85 \mathrm{~W}$; $V_{\mathrm{oc}}=22.2 \mathrm{~V} ; I_{\mathrm{sc}}=5.45 \mathrm{~A} ; V_{\max }=17.2 \mathrm{~V} ; I_{\max }=$ $4.95 \mathrm{~A}$.
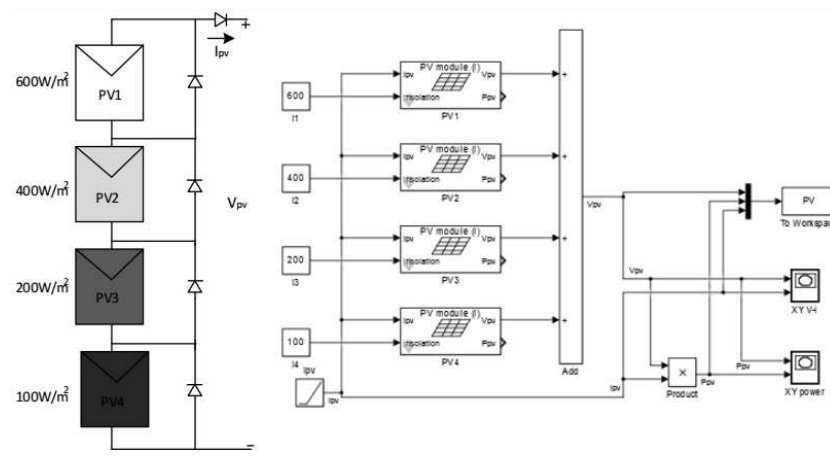

Fig. 3. MATLAB simulation environment of PV array under PSC.

Output characteristics of PV array were simulated under PSC, as shown in Fig. 3. Multiple peaks shown in Fig. 4 i.e, local and global maxima points are observed in the $P-V$ curve due to the existence of bypass diodes.

\section{MPPT methods for PSC}

After the realization of the existence of PSC effect in PV modules, studies about MPPT methods for PSC have rapidly spread in the literature. There are various kinds of methods, presented for non-uniform insolation conditions, however for designers it is getting harder to make

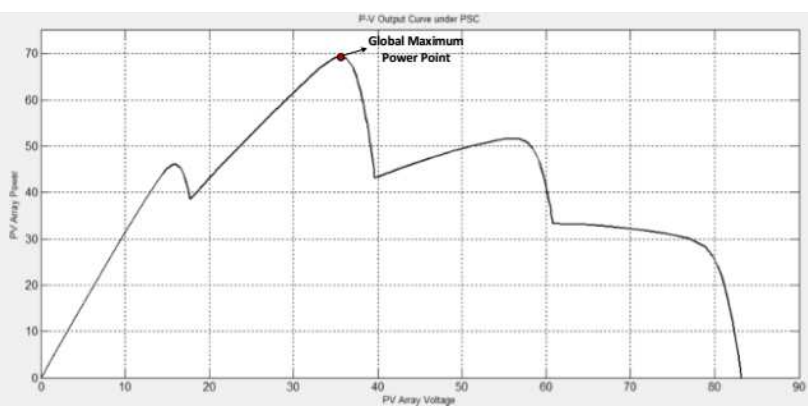

Fig. 4. $P-V$ curve under PSC.

the right choice for their specific applications. Every specific application has its priorities, such as efficiency, cost, accuracy, implementation complexity etc. To make a factual comparison, in this study, first of all, the selected studies were grouped into six general sections, shown in Table I.

TABLE I

MPPT methods for PSC.

\begin{tabular}{|c|c|}
\hline $\begin{array}{l}\text { Meta-heuristics } \\
\text { methods }\end{array}$ & $\begin{array}{c}\text { Modified PSO [7] } \\
\text { Simulated annealing [8] } \\
\text { Grey-Wolf optimization [9] } \\
\text { DEPSO [10] } \\
\text { Firefly colony [11] } \\
\text { Artificial bee colony [12] }\end{array}$ \\
\hline $\begin{array}{c}\text { Fuzzy logic } \\
\text { based methods }\end{array}$ & $\begin{array}{c}\text { Hill-climbing based FL [1] } \\
\text { FL based experimental } \\
\text { evaluation [13] }\end{array}$ \\
\hline $\begin{array}{c}\text { Numerical } \\
\text { and mathematical } \\
\text { application methods }\end{array}$ & $\begin{array}{c}\text { Lambert W function [14] } \\
\text { Voltage window [2] } \\
\text { Kalman filter [15] } \\
\text { Analytical modelling } \\
\text { of PV system [16] }\end{array}$ \\
\hline $\begin{array}{c}\text { Modified conventional } \\
\text { methods }\end{array}$ & $\begin{array}{c}\text { Modified P\&O [3] } \\
\text { Modified INC [17] } \\
\text { P\&O based PSO [18] }\end{array}$ \\
\hline Hardware solutions & $\begin{array}{c}\text { Neutral point clamped [19] } \\
\text { Switching PV modules [4] } \\
\text { DC-DC control [20] } \\
\text { PV Su Do Ku configuration [21] } \\
\text { LLC resonant [22] }\end{array}$ \\
\hline Other methods & $\begin{array}{c}\text { Two stage [23] } \\
\text { Real MPPT [24] }\end{array}$ \\
\hline
\end{tabular}

\subsection{Meta-heuristics}

This group involves meta-heuristic based algorithms used in MPPTs. Within the meta-heuristic algorithms, particle swarm optimization (PSO) is the most used algorithm in literature, thanks to its simple implementation and powerful behaviour at PSC. Other methods in this group are, simulated annealing [8], Grey-Wolf optimization [9], DEPSO [10], firefly colony [11] and artificial bee 
colony. All these algorithms are investigated for advantages and drawbacks in the following sub-sections.

Reference [7] presents a deterministic PSO (DPSO) algorithm to improve the global maximum tracking ability of MPPTs under PSC. This paper focused on the removing the random numbers from the accelerations factor of the PSO velocity equation. The proposed approach claims to improve following features in MPPTs:

- The particles track a deterministic behaviour.

- Only one parameter i.e., the inertia weight, needs to be tuned.

- The optimization structure is much simpler, compared to conventional PSO.

- The algorithm can be very useful in frequently changing environmental conditions.

The drawbacks of this proposed DPSO method are listed below:

- There is a big difference between the array currents in the low and high voltages of the array.

- To detect PSC the array current samples low and high voltages, cause a big disturbance in the system.

- The comparison curves with conventional PSO method have not been adequately covered, therefore the superiority of the proposed method was not highlighted enough.

Paper [8] proposes a simulated annealing-based (SA) global maximum power point tracking technique designed for PSC. The SA method is based on following the heating and cooling processes in metals to find the global optimum solution. The energy measured during the heating and cooling process is compared to the current reference state. If the new operating point has more energy, the new working point is selected as the new one, otherwise, it can be changed depending on the acceptance probability. When compared with PSO and P\&O methods, this study showed that the computational complexity was large due to the parameters held in memory in each iteration and the algorithm could not capture GMPP each time.

The Grey-Wolf optimization (GWO) method is presented in [9] as an algorithm that overcomes such problems as steady-state oscillations, lower tracking efficiency, which are encountered in P\&O and PSO methods. The proposed method detects the shading pattern variations and is faster to converge to the global maximum, and has reduced steady-state oscillations.

However, this algorithm has some disadvantages, especially in the implementation part. The GWO has a complex initialization part and there are lots of unknown parameters that have to be determined by the designer.

The DEPSO [10] technique is a combination of the differential evolutionary (DE) algorithm and particle swarm optimization (PSO), to detect the MPP under PSC. The benefits of the DEPSO are reliability, systemindependence and accuracy in tracking the GMPP. In the results of the DEPSO, chattering range values are considerably high, when compared with other methods.

Study [11] aims to overcome the PSC problem in MPPTs by using the firefly algorithm. The proposed method has some advantages, such as easy calculation steps, faster convergence and lower cost. Although the chattering range in $\mathrm{PV}$ power seems superior, when compared with conventional PSO, it is still higher than in the improved PSO algorithms.

Paper [12] proposes an artificial bee colony (ABC) algorithm for global MPP. The proposed method reduces the tracking time of GMPP, compared with PSO and enhanced $\mathrm{P} \& \mathrm{O}(\mathrm{EPO})$. The comparison results indicate that, ABC method is slightly better than PSO and EPO in efficiency and convergence GMPP time parameters, however, the implementation complexity of this method is quite high, compared to other methods.

\subsection{Fuzzy logic based methods}

A hill climbing-based FL method is proposed in paper [1]. Here the MPP's values are periodically stored in a DSP and FL is later implemented to track the GMPP, based on the records. In study [1], the entire $P-I$ curve is scanned to find the global maximum in micro grids. Subsequently, the change in the operating working point is calculated. If the predetermined difference value is larger then expected, the duty cycle is changed, otherwise, the operating point is left intact and this can cause considerable power loss in large measuring PV systems. In addition to this drawback, perturbing and storing all possible MPPs causes long processing time and the use of FL also improves implementation complexity.
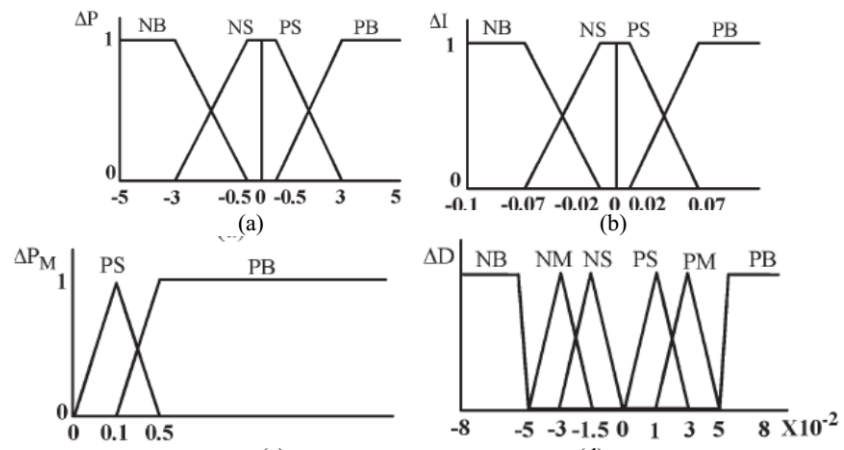

(c)

(d)

Fig. 5. Example of membership functions for the fuzzy model in partial shade $\mathrm{PV}$ applications (a) input $\Delta P$, (b) input $\Delta I$ (c) input $\Delta P_{M}$ and (d) input $\Delta D$.

Fuzzy logic control generally consists of three stages: fuzzification, rule base table lookup, and defuzzification. During fuzzification, numerical input variables are converted into linguistic variables, based on a membership function, similar to Fig. 5. In this case, five fuzzy levels are used: NB (negative big), NS (negative small), 
PS (positive small), and PB (positive big). In Fig. $5 \mathrm{FL}$ levels are based on the range of values of the numerical variable [1].

Paper [13] presents a FL based experimental evaluation method to detect GMPP for stand-alone PV systems. This method, scans the $P-V$ curve and locates the operating point near GMPP. Later the FL method detects the real GMPP. Entire algorithm runs on an advanced microcontroller. Simulation and experimental results of the proposed method are compared with classical $\mathrm{P} \& \mathrm{O}$ method. Comparisons in this report shows that the proposed method has long scanning time, of $30 \mathrm{~ms}$, which can lead to serious power losses in a large scale PV system.

\subsection{Numerical and mathematical application methods}

Paper [14] presents a new version of single-diode model of a PV cell with the help of Lambert W function, which is permitting calculation of the MPP in a straightforward manner, without any need for a numerical solution. The MPP is directly calculated from derived equations in the manuscript, under uniform or non-uniform insolation levels. Although, the calculation method of the MPP is simple, the real global peak cannot be guaranteed under every PSC.

Report [2] studies voltage window (VW) method, which limits the global maximum searching area, that helps to speed up the algorithm and reduce the power loss. However, this limitation may cause the global maximum area to be missed under some PSCs. In this case the power loss would be greater, and the proposed algorithm may be trapped into the local maxima.

Study [15] estimates the global maximum power point by using Kalman filter technique. The design and application processes of this proposed algorithm are complex and require an advanced microcontroller during the implementation part.

In [16], as a first step, the researchers try to analytically model the PV system, which is connected to the grid. In this study, authors aim to mathematically analyze a single module under partial shade conditions. Therefore, a multi-dimensional structure of the PV system is determined, which allows to find a cost effective configuration of the PV arrays.

\subsection{Modified conventional methods}

The method proposed in [17] evolves the conventional P\&O method to track the GMPP. The flowchart of the proposed algorithm is shown in Fig. 6. Although, it has a good performance under PSC, it requires to measure the voltage of each module, and that may increase the total cost for large scale PV systems and increase the implementation complexity.

An improved IC algorithm, which is based on IC and sampling the $P-V$ characteristic of the array in intervals of $0.8 \mathrm{~V}_{\text {oc-mod }}$ is proposed in [15] to improve the MPP tracking capability during PSC. The effect of PSC diminishes the efficiency of modified conventional algorithms.

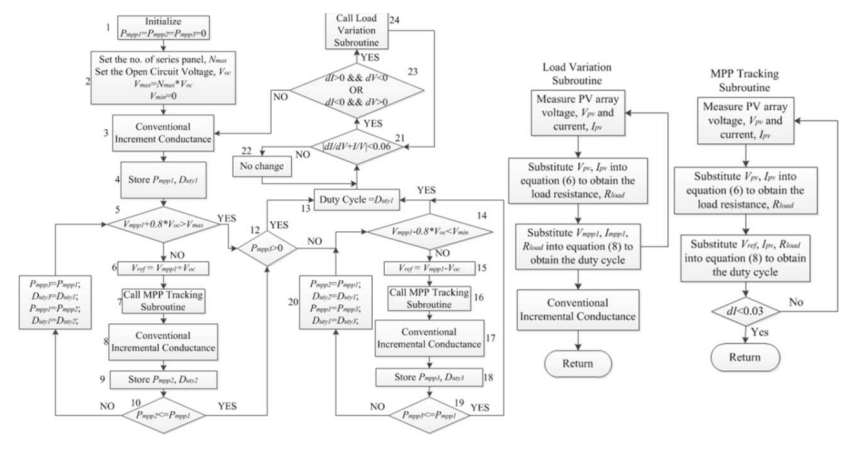

Fig. 6. Flowchart of the algorithm proposed in [15].

This method, limits the search area for GMPP and yields suitable results, but needs high sampling number, which increases the complexity.

Reference 18 presents a hybrid algorithm by combining $\mathrm{P} \& \mathrm{O}$ and PSO techniques together. In this hybrid technique, $\mathrm{P} \& \mathrm{O}$ is performed under uniform insolation conditions, when PSC occurs the PSO is employed. In addition, PSO search area is reduced by using window based search, to reduce the power oscillations and convergence time. The drawback of this method is that if the partial shade detection fails, algorithm will never shift to the PSO. For this reason $\mathrm{P} \& \mathrm{O}$ algorithm can be trapped at the local maximum.

\subsection{Hardware methods}

In most PV systems, the centralized topology is used for its low cost and easy control features, however in the case of PSC, the global maximum search algorithm is required. To overcome this problem, multistring inverter topology is proposed. In this topology, each PV module is connected to a DC/DC converter. Although, this multistring method allows the use of conventional MPPT algorithms even under PSC, this increases the cost and control complexity of the system.

Similarly to multistring technology, study [19] proposed a two capacitor voltage method. Capacitors are controlled asymmetrically to allow each PV module to be connected to the MPPT separately. However as mentioned before, this method increases implementation complexity because it requires space vector switching control and complex matrix calculations. In addition, the multistring technology increases the number of switching IGBT's, which reduces the efficiency of the whole PV system dramatically.

Study [5] presents a PV switch technique to enhance the maximum power under PSC. In the proposed system, each string in the PV array is divided into two equal sections; in state one, the highest possible output voltage is the open circuit voltage of the whole string and in state two, the highest output voltage is the half of the open circuit voltage of the whole string. This method is easy to implement and low cost, however because of low-efficiency levels this method is only useful for small scale PV systems. 
Study [20] suggests a GMPPT search algorithm using constant-power operation. However, trying to perceive small power changes between local maxima slows down the algorithm extremely. In addition, there is a need for a constant-input-power DC-DC converter, which increases cost.

In study [21], the physical arrangement of PV modules for PSC situations is proposed. The modules are physically rearranged according to the $\mathrm{Su}-\mathrm{Do}-\mathrm{Ku}$ puzzle pattern, without changing their electrical connection. The shading effect is distributed over the array, which results in increasing power, drawn from the PV system. However, since these systems require long connections when they are evaluated, they cause serious line losses.

The two-switch equalizer, using an LLC resonant voltage multiplier is studied in [22]. The switch count can be dramatically reduced with this proposed method, but it still requires two switches, which will increase the complexity and reduce the system efficiency.

\subsection{Other methods}

In the first stage of method [23], the PSC is determined, and in the second stage, the MPP point is reached by taking the continuous sampling from the $P-V$ characteristic curve of the array and depending on the change in duty cycle. The detection method of PSC is not reliable, for this reason this method could not guarantee the GMPP under every PSC.

The incremental conductance algorithm has been modified to perform a simple linear equation for monitoring the GMPP [24]. The hardware complexity in this method requires additional measuring circuits at the inverter output. In addition, monitoring of GMPP is not provided for the $P-V$ curve, which has more than two peaks.

\section{Comparison of results}

In the previous sections, the methods developed in the literature for the PSC cases have been grouped and evaluated with their advantages and drawbacks. In this section, Table II is prepared with the aim of giving a brief evaluation of the related studies to the designers. In Table II, all studies of this review were evaluated from the point of view of speed, global maximum power point detection, implementation complexity, efficiency and cost. The corresponding abbreviations in the table are as follows; MG: method group; RN: reference number; $\mathrm{S}$ : speed; GMPP: global maximum power point; IC: implementation complexity; E: efficiency; C: cost; FLB: fuzzy logic based; NM: numerical methods; MC: modified conventional; OM: other methods; H: high; L: low; F: fast; M: medium; S: slow; NFA: not for all conditions; Y: yes; $\mathrm{N}$ : no; AG: around GMPP.

Comparison table for MPPT algorithms under PSC.

\begin{tabular}{|c|c|c|c|c|c|c|c|}
\hline $\mathrm{MG}$ & MPPT algorithm & $\mathrm{RN}$ & $\mathrm{S}$ & GMPP & $\mathrm{IC}$ & $\mathrm{E}$ & $\mathrm{C}$ \\
\hline \multirow[t]{6}{*}{ Meta-heuristics } & Modified PSO & {$[7]$} & $\mathrm{M}$ & NFA & $\mathrm{M}$ & $\mathrm{M}$ & $\bar{M}$ \\
\hline & Simulated annealing & [8] & $\mathrm{F}$ & AG & $\mathrm{H}$ & $\mathrm{H}$ & $\mathrm{H}$ \\
\hline & Grey-Wolf optimization & [9] & $\mathrm{H}$ & $\mathrm{Y}$ & $\mathrm{H}$ & $\mathrm{H}$ & $\mathrm{H}$ \\
\hline & DEPSO & [10] & $\mathrm{M}$ & Y & $\mathrm{H}$ & $\mathrm{L}$ & $\mathrm{H}$ \\
\hline & Firefly colony & [11] & $\mathrm{H}$ & Y & $\mathrm{H}$ & M & $\mathrm{H}$ \\
\hline & Artificial bee colony & [12] & M & $\mathrm{Y}$ & M & M & M \\
\hline \multirow[t]{2}{*}{ FLB } & Hill-climbing based FL & {$[1]$} & $\mathrm{S}$ & $\mathrm{Y}$ & $\mathrm{H}$ & $\mathrm{M}$ & $\mathrm{H}$ \\
\hline & FL based experimental evaluation & [13] & M & $\mathrm{Y}$ & M & $\mathrm{L}$ & M \\
\hline \multirow{4}{*}{ NAM } & Lambert $\mathrm{W}$ function & [14] & $\mathrm{F}$ & NFA & $\mathrm{L}$ & $\mathrm{M}$ & $\bar{M}$ \\
\hline & Voltage window & {$[2]$} & M & NFA & M & M & M \\
\hline & Kalman filter & [15] & $\mathrm{F}$ & $\mathrm{Y}$ & $\mathrm{H}$ & $\mathrm{H}$ & $\mathrm{H}$ \\
\hline & Analytical modelling of PV system & [16] & $\mathrm{F}$ & NFA & $\mathrm{H}$ & $\mathrm{H}$ & M \\
\hline \multirow[t]{3}{*}{$\mathrm{MC}$} & Modified P\&O & {$[4]$} & $\mathrm{F}$ & NFA & $\mathrm{H}$ & $\mathrm{M}$ & $\mathrm{H}$ \\
\hline & Modified INC & {$[17]$} & $\mathrm{F}$ & NFA & $\mathrm{H}$ & M & $\mathrm{H}$ \\
\hline & $\mathrm{P} \& \mathrm{O}$ based PSO & [18] & $\mathrm{F}$ & NFA & M & M & M \\
\hline \multirow[t]{5}{*}{ Hardware } & Neutral point clamped & [19] & $\mathrm{F}$ & $\mathrm{Y}$ & $\mathrm{H}$ & $\mathrm{M}$ & $\bar{M}$ \\
\hline & Switching PV modules & {$[5]$} & M & Y & M & $\mathrm{L}$ & M \\
\hline & DC-DC control & [20] & $\mathrm{S}$ & $\mathrm{Y}$ & $\mathrm{H}$ & M & $\mathrm{H}$ \\
\hline & PV Su Do Ku conf. & [21] & $\mathrm{M}$ & NFA & $\mathrm{H}$ & $\mathrm{L}$ & $\mathrm{H}$ \\
\hline & LLC resonant & {$[22]$} & $\mathrm{F}$ & $\mathrm{Y}$ & M & M & M \\
\hline \multirow[t]{2}{*}{$\mathrm{OM}$} & Two stage & [23] & $\mathrm{M}$ & NFA & $\mathrm{M}$ & $\mathrm{M}$ & $\overline{\mathrm{M}}$ \\
\hline & Real MPPT & {$[24]$} & M & NFA & $\mathrm{H}$ & M & \\
\hline
\end{tabular}


This table is aimed to facilitate the selection of the relevant work in accordance with the designers' priorities and to guide the researchers.

\section{Conclusions}

In the literature there are a large number of studies on finding the GMPP for PSC. It is extremely difficult for the designer to determine the proper study in this sea of knowledge. For this reason, this review study has criticized the selection of important and feasible studies in the literature, revealing the advantages and disadvantages of each work. In addition, this study classifies the studies from the literature into six main groups. After the relevant evaluations of all studies, a summary table has been presented, which enables to select an appropriate study in a very short time, according to the design priorities of the designers.

\section{References}

[1] B.N. Alajmi, K.H. Ahmed, S.J. Finney, B.W. Williams, B. Wayne Williams, IEEE Trans. Ind. Electron. 60, 1596 (2011).

[2] M. Boztepe, F. Guinjoan, G. Velasco-Quesada, S. Silvestre, A. Chouder, E. Karatepe, IEEE Trans. Ind. Electron. 61, 3302 (2014).

[3] Z. Er, I.B. Turna, Acta Phys. Pol. A. 129, 865 (2016).

[4] K. Chen, S. Tian, Y. Cheng, L. Bai, IEEE Trans. Sustain. Energy 5, 978 (2014).

[5] A.A. Elserougi, M.S. Diab, A.M. Massoud, A.S. Abdel-Khalik, S. Ahmed, IEEE Trans. Sustain. Energy 6, 767 (2015).

[6] A.A. Jadallah, D.Y. Mahmood, Z.A. Abdulqader, Acta Phys. Pol. A. 128, B-461 (2015).

[7] K. Ishaque, Z. Salam, IEEE Trans. Ind. Electron. 60, 3195 (2013).

[8] S. Lyden, M.E. Haque, IEEE Trans. Power Electron. 31, 4171 (2016).
[9] S. Mohanty, B. Subudhi, P.K. Ray, IEEE Trans. Sustain. Energy 7, 181 (2016).

[10] M. Seyedmahmoudian, R. Rahmani, S. Mekhilef, A. Maung Than Oo, A. Stojcevski, T.K. Soon, A.S. Ghandhari, IEEE Trans. Sustain. Energy 6, 850 (2015).

[11] K. Sundareswaran, S. Peddapati, S. Palani, IEEE Trans. Energy Convers. 29, 463 (2014).

[12] K. Sundareswaran, P. Sankar, P.S.R. Nayak, S.P. Simon, S. Palani, IEEE Trans. Sustain. Energy 6, 198 (2015).

[13] N. Shah, C. Rajagopalan, IET Renew. Power Gener. 10, 98 (2016).

[14] E.I. Batzelis, G.E. Kampitsis, S.A. Papathanassiou, S.N. Manias, IEEE Trans. Energy Convers. 30, 226 (2015).

[15] B.K. Kang, S.T. Kim, S.H. Bae, J.W. Park, IEEE Trans. Energy Convers. 27, 885 (2012).

[16] M. Seyedmahmoudian, S. Mekhilef, R. Rahmani, R. Yusof, E.T. Renani, Energies 6, 128 (2013).

[17] K.S. Tey, S. Mekhilef, IEEE Trans. Ind. Electron. 61, 5384 (2014).

[18] C. Manickam, G.R. Raman, G.P. Raman, S.I. Ganesan, C. Nagamani, IEEE Trans. Ind. Electron. 63, 6097 (2016).

[19] U.M. Choi, F. Blaabjerg, K.B. Lee, IEEE Trans. Ind. Appl. 51, 3295 (2015).

[20] E. Koutroulis, F. Blaabjerg, IEEE J. Photovoltaics 2, 184 (2012).

[21] B.I. Rani, G.S. Ilango, C. Nagamani, IEEE Trans. Sustain. Energy 4, 594 (2013).

[22] M. Uno, A. Kukita, IEEE Trans. Ind. Appl. $\mathbf{5 1}$ 1587 (2015).

[23] M.A. Ghasemi, H. Mohammadian Forushani, M. Parniani, IEEE Trans. Power Electron. 31, 6281 (2016).

[24] Y.H. Ji, D.Y. Jung, J.G. Kim, J.H. Kim, T.W. Lee, C.Y. Won, IEEE Trans. Power Electron. 26, 1001 (2011). 